\title{
- l PAPEl DEL VALENCIANO JUAN MONLEóN SAPIÑA EN LA RESTAURACIÓN DEL MONASTERIO DE SAMOS ENTRE 1953 Y 1960'
}

\author{
ESTEFANÍA LÓPEZ SALAS \\ Universidade da Coruña \\ estefania.Isalas@udc.es
}

\begin{abstract}
Resumen: El artículo que a continuación se desarrolla tiene por objetivo el estudio del proyecto de restauración redactado y dirigido por Juan Monleón Sapiña, oblato regular de la comunidad monacal de San Julián de Samos (Lugo-España), con motivo de recuperar las zonas dañadas de los dos claustros de la citada fábrica monástica, a raíz del incendio del 24 de septiembre de 1951. A partir de un conjunto de documentación escrita y gráfica, intentamos profundizar en el conocimiento de los trabajos desarrollados entre 1953, fecha de inicio de las obras, y 1960, año de la reapertura del monasterio; a la vez que aportamos datos inéditos sobre una etapa reciente, pero con grandes consecuencias sobre la arquitectura monacal actual.
\end{abstract}

Palabras clave: San Julián de Samos / monasterio / siglo XX / Juan Monleón Sapiña / restauración.

Abstract: The present article aims to study the project of restoration that was designed and ran by Juan Monleón Sapiña, who was an oblate of the monastic community of San Julián de Samos (Lugo-Spain). This project was carried out to recover the cloisters, which were damaged during the fire that took place on the $24^{\text {th }}$ September 1951. Based on archival sources and graphic documents, we aim to go deeply into the understanding of all the works that were undertaken between 1953, which is the commencement date, and 1960, when the monastery was reopened. In addition to that, we gathered new data concerning a fairly recent period in the long life of this monastery, but also one with significant changes in its current architecture.

Key words: San Julián de Samos / monastery / 20 ${ }^{\text {th }}$ century / Juan Monleón Sapiña / restoration.

En julio de 1951, Juan Monleón Sapiña (Valencia, 27 de julio de 1888 - Samos, 10 de agosto de 1976) ${ }^{2}$ ingresaba en el monasterio lucense de San Julián de Samos como oblato regular. ${ }^{3}$ Su llegada tenía lugar tan sólo dos meses antes del incendio que, el 24 de septiembre, se originó de forma inesperada en esta antigua casa religiosa gallega, afectando gravemente a la mayor parte de sus dependencias y frenando, de forma repentina, el desarrollo de su tranquila vida monacal. La experiencia previa de Juan Monleón, como arquitecto e ingeniero, ${ }^{4}$ lo convirtió en el miembro de la co-

* Fecha de recepción: 15 de enero de 2017 / Fecha de aceptación: 20 de junio de 2017.

1 El presente trabajo constituye una parte de mi tesis doctoral, titulada San Julián de Samos-Lugo, estudio e interpretación del diseño monástico y su evolución, dirigida por José Ramón Soraluce Blond y defendida en junio de 2015 . Fue financiada por la Universidad de A Coruña (Ref.: Ayuda de apoyo a la etapa pre-doctoral UDC 2011) y por la Consellería de Cultura, Educación y Ordenación Universitaria de la Xunta de Galicia (Ref.: Ayuda de apoyo a la etapa pre-doctoral del Plan Gallego de Investigación, Innovación y Crecimiento 2011-2015 - Plan IC2), cofinanciado por el Fondo Social Europeo (FSE-FEDER).

Asimismo, la autora quiere agradecer a la comunidad benedictina de San Julián de Samos, en especial al P. José Luis Vélez Álvarez y al P. Agustín Miguélez Vecillas, las facilidades recibidas para acceder al archivo monacal con el fin de consultar libremente el conjunto de documentos inéditos que han servido de base para el desarrollo de este trabajo.

2 GARRIDO MORENO, Antonio, 2008, pp. 181, 191.

3 ARMESTO, Alejandro, 1960, p. 52.

${ }^{4}$ Los diferentes autores que han estudiado el trabajo de Juan Monleón Sapiña en el monasterio de Samos tras el incendio de 1951 aportan distintos datos en lo que a su formación profesional se refiere. Rivera Manso (1960) indica que fue arquitecto e ingeniero industrial. El benedictino Portilla Costa (2003: 53) señala que era arquitecto e ingeniero de profesión, sin especificar de qué. Sin embargo, en unos documentos de este monje de Samos, a los que hemos tenido acceso en el archivo del monasterio, encontramos una serie de anotaciones manuscritas sobre Juan Monleón Sapiña en las que señala que estudió en Lieja para ser ingeniero electromecánico y que en Madrid hizo dos o tres cursos de arquitectura. Por último, el trabajo más reciente realizado sobre este tema por Garrido Moreno (2008: 181) recoge que Juan Monleón Sapiña era arquitecto e ingeniero de caminos, canales y puertos. 
munidad benedictina más preparado para capitanear el necesario proceso de restauración que, a raíz de las consecuencias del incendio sobre la fábrica monacal, fue necesario iniciar.

En el presente artículo nos proponemos estudiar el papel que este oblato regular, de origen valenciano, jugó en los trabajos de restauración de los dos claustros que se llevaron a cabo entre 1953 y 1960, a través del análisis de un conjunto de documentos inéditos que hoy se conservan en el archivo del monasterio de San Julián de Samos.

A diferencia de lo ocurrido con las partes dañadas de las cubiertas de la iglesia, la sacristía y el signo, cuyo proyecto de reconstrucción fue planteado y dirigido desde Madrid por arquitectos estatales; ${ }^{5}$ las obras de restauración de los dos claustros fueron asumidas directamente por la comunidad religiosa de Samos. La enorme dimensión del espacio afectado por el incendio $y$, principalmente, el elevado número de ventanas y puertas diferentes que era necesario diseñar y construir de nuevo, hacían muy dificultosa tanto la redacción del proyecto como su dirección desde la capital del Estado ${ }^{6}$ y obligaban a una concepción y conducción de los trabajos in situ. Esta tarea recayó en Juan Monleón Sapiña y a su análisis dedicamos el presente trabajo.

\section{Los primeros pasos}

Tras la retirada de los escombros y antes del inicio de las obras, la primera tarea fue redactar el proyecto de reconstrucción. Para ello, Juan Monleón Sapiña dibujó pacientemente los planos de las tres plantas de los dos claustros, herramienta fundamental para, posteriormente, enfrentarse a la resolución de cada una de las múltiples estancias que conforman el monasterio. ${ }^{7}$

Estos tres documentos, que se conservan actualmente en el archivo de la casa religiosa, muestran la propuesta inicial de reconstrucción (fig. 1). En ellos se planteaban ligeros cambios en cuanto a la distribución de las dependencias en planta baja y algunas novedades en la resolución de las alturas segunda y tercera que afectaban a los elementos de comunicación vertical y, sobre todo, a la aparición de nuevas celdas. Por otra parte, la importan-
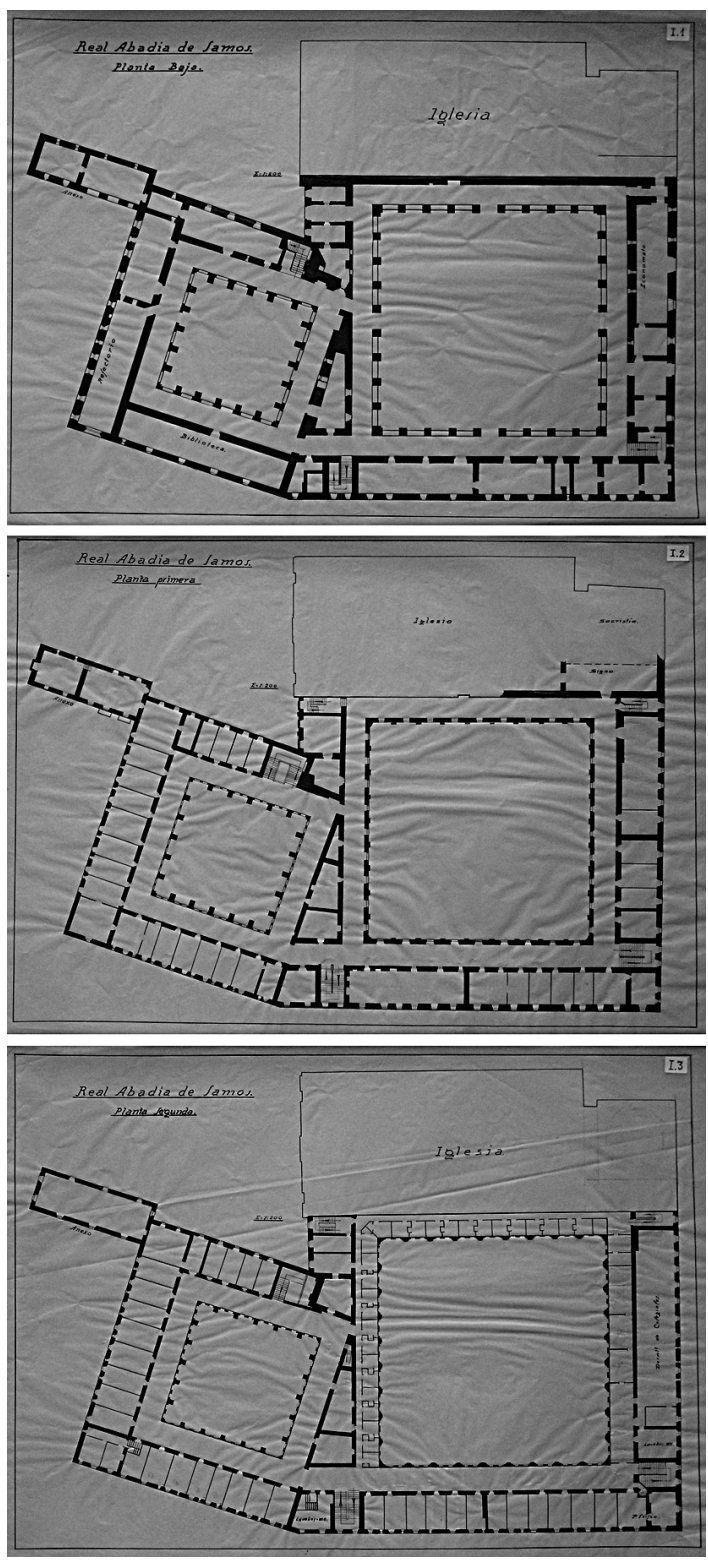

Fig. 1. De arriba a abajo, plantas baja, primera y segunda del monasterio dibujadas por Juan Monleón Sapiña para el proyecto de reconstrucción tras el incendio de 1951. (C) Archivo del Monasterio de San Julián de Samos.

cia de estos tres documentos radica en el hecho de que constituyen los primeros planos que se conservan del monasterio con las plantas completas de ambos claustros, dibujadas de forma bastante rigurosa, pues el único plano publicado con

\footnotetext{
5 Proyecto de reconstrucción de armaduras y restauración de cubiertas en la iglesia y sacristía del monasterio de Samos, en Archivo General de la Administración (en adelante, AGA), Expedientes de restauración de monumentos, sign. 26/00298. A este proyecto hacen referencia CASTRO FERNÁNDEZ, Belén, 2007, pp. 529-535; LÓPEZ SALAS, Estefanía, 2016, pp. $443-445$.

6 GARRIDO MORENO, Antonio, 2008, p. 182; GOZALO, Miguel Ángel, 1960, p. 5.

7 Archivo del Monasterio de Samos (en adelante, AMS), Proyecto de reconstrucción del monasterio tras el incendio de 1951 , carpeta I, planos I-1, I-2, I-3.
} 
anterioridad por el arquitecto Miguel Durán (A Coruña, 1886 - Madrid, 1950), aunque con mayor grado de detalle, solamente representaba el nivel inferior de los claustros y el espacio interior de la iglesia ${ }^{8}$ que, por no verse afectada por el incendio, ahora no era objeto de actuación.

Delineado el espacio en su conjunto, se procedió a la elaboración de planos con más detalle que permitieran estudiar con precisión la nueva distribución de las celdas, plantear la conformación de los nuevos pavimentos, resolver los alzados interiores de cada una de las naves, diseñar la forma de fabricar las nuevas puertas... El trabajo de pensar y dibujar el espacio de las dependencias y de todos y cada uno de los elementos perdidos durante el incendio que era necesario reconstruir, conllevó muchas horas. Por ello, a diferencia de las plantas generales, básicas para el arranque de las obras y posiblemente elaboradas en 1952, los demás planos se fueron realizando a lo largo de los nueve años que duraron los trabajos de restauración.

Hablando de Juan Monleón Sapiña decía un periodista en 1960, con motivo de la inauguración del monasterio, que "Él se ha pasado muchas horas sobre la mesa de trabajo, con la tinta china y el tiralíneas, entre plantillas de papel vegetal, dibujando, amorosamente, las nuevas perspectivas. Y, aunque no le gusta decirlo -y menos aún que yo lo diga ahora-, no hay nada en el nuevo Samos que no haya pasado antes por su mesa". 9

El dibujo detallado de la realidad conservada y de la propuesta de actuación era una tarea primordial para conseguir que la intervención fuese respetuosa con la envergadura e historia de la obra arquitectónica en la que se planteaba la actuación de recuperación. De modo muy resumido, podemos decir que el monasterio de San Julián de Samos era, en el momento que tuvo lugar el incendio, un gran palimpsesto arquitectónico, con múltiples partes realizadas, transformadas o superpuestas en distintas épocas. Del periodo medieval se mantienen en pie la llamada capilla del Ciprés y algunos restos del antiguo templo románico, derribado casi de forma completa para la construcción, desde finales del siglo XVII y hasta mediados del siglo XVIII de la iglesia actual y el llamado claustro grande o del P. Feijóo. El otro claustro del monasterio, el conocido como de las Nereidas, se empezó a levantar hacia finales del siglo XVI y, su última planta, al igual que en el caso del claustro grande, no se llegó a construir hasta la segunda mitad del siglo XVIII. En definitiva, se encontraban ante una obra con una larga trayectoria temporal, que requería de un estudio minucioso de cada una de sus múltiples partes y de una respuesta acorde a su importancia histórico-artística, a las necesidades de la comunidad religiosa existente y a los requisitos funcionales propios de una nueva época.

\section{Arranque de las obras: la reconstrucción de la estructura de cubierta y de forjados}

Al igual que la redacción y dirección del proyecto estaban en manos de un miembro de la comunidad benedictina, en la ejecución de las obras participaron los propios monjes, ${ }^{10}$ que contaron con la ayuda de un conjunto reducido de obreros, distribuidos en grupos de albañiles, carpinteros y canteros (fig. 2). En su mayor parte eran vecinos de la villa de Samos o de otros núcleos cercanos, con poca experiencia, a excepción de la media docena de canteros procedentes de Pontevedra. ${ }^{11}$

Parte de los fondos recaudados durante los dos primeros años posteriores al incendio, se emplearon en la compra del material necesario, como hierro, cemento, perfiles laminados..., aunque las gestiones para conseguirlos fueron difíciles dado que muchos de ellos "estaban intervenidos y tasados por el Estado". ${ }^{12}$

De igual forma, y con la finalidad de conseguir que las obras se desarrollaran lo más rápido posible desde el inicio, y que su coste fuera menor, en lugar de seguir los métodos de contratación normales, la comunidad instaló en el monasterio una carpintería en la que, bajo la dirección del hermano Jaime, se realizaban las nuevas ventanas y puertas de madera y el mobiliario; así como una herrería con todos los servicios necesarios para la fabricación de las nuevas ventanas metálicas y la

\footnotetext{
8 DURÁN, Miguel, 1947, Fig. I. Sobre el arquitecto Miguel Durán Salgado se pueden consultar los siguientes trabajos: "In memoriam: Don Miguel...", 1946-1950, pp. 185-187; LÓPEZ OTERO, Modesto, 1950, p. 327.

9 GOZALO, Miguel Ángel, 1960, p. 5. Citado por PORTILLA COSTA, Pedro de la. Monasterio de San Julián de Samos. Historia de dos restauraciones (1880 y 1951). A Coruña: Fundación Caixa Galicia, 2003, p. 53.

10 ARIAS CUENLLAS, Maximino, 1992, p. 494; PORTILLA COSTA, Pedro de la, 2003, p. 53.

11 ARMESTO, Alejandro, 1960, p. 52.

12 Memoria de las obras y mejoras efectuadas desde 1930 a 1959, en AMS, Papeles del tiempo del abad Mauro Gómez (19301972), carpeta F10, sin foliar; ARIAS CUENLLAS, Maximino, 1992, p. 491; PORTILLA COSTA, Pedro de la, 2003, p. 50.
} 

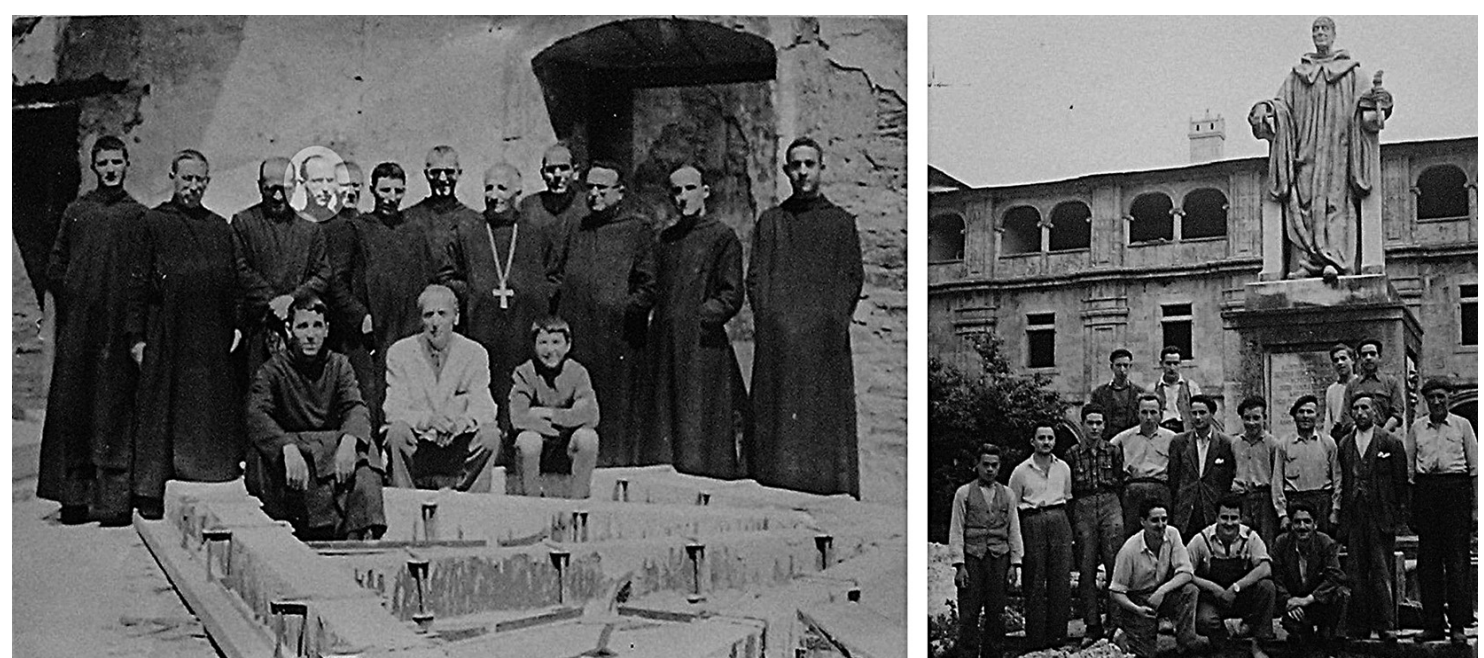

Fig. 2. De izquierda a derecha, los monjes y los obreros que participaron en la restauración del monasterio. Entre los monjes se señala el rostro de Juan Monleón Sapiña. (C) Fondo Fotográfico del Monasterio de San Julián de Samos.

cerrajería, a cuyo frente se encontraba el hermano Gregorio Dobarro. ${ }^{13}$

Pensado el proyecto, reunido el material, el personal y organizados los distintos talleres de trabajo específicos, las obras comenzaron en 1953. El primer paso fue la reconstrucción de las cubiertas de ambos claustros y de los forjados situados entre la planta segunda y tercera que había destruido completamente el incendio. La reposición de las primeras era la tarea más urgente para evitar que las Iluvias provocasen un aumento de los ya más que considerables daños existentes.

Aunque la estructura original de soporte de las cubiertas y del piso del monasterio era de madera, el redactor del proyecto, posiblemente siguiendo las recomendaciones de un informe emitido por los arquitectos estatales en octubre de 1951, ${ }^{14}$ no consideró oportuno mantener esa solución y, en su lugar, apostó por el uso de la técnica moderna, "procurando la incombustibilidad de todos sus elementos y la conservación del estilo y decorado artístico adecuado a un monasterio que ha sido calificado como Monumento Nacional". ${ }^{15}$
Esta postura estaba muy vinculada a las recomendaciones básicas que las actas o carta de la Conferencia internacional de expertos en la protección y conservación de monumentos de arte y de historia, celebrada en Atenas en octubre de 1931, recogían en cuanto a los materiales que debían de ser utilizados en una reconstrucción. En ellas se aprobaba "el empleo juicioso de todos los recursos de la técnica moderna, muy especialmente del hormigón armado"16 $\mathrm{y}$, al mismo tiempo, expresaban "la opinión de que normalmente estos medios de refuerzo deben estar disimulados para no alterar el aspecto y carácter del edificio a restaurar". ${ }^{17}$

Con una posición claramente definida y seguidora de las teorías de restauración europeas, la estructura de las nuevas cubiertas del monasterio se resolvió con "armaduras o cerchas trianguladas de 10 a $13 \mathrm{~m}$ de luz, construidas con cemento armado, así como también la viguería que apoya en ellas, cerrando los huecos intermedios con doble bovedilla de cemento". ${ }^{18} \mathrm{Nada}$ de esa nueva estructura era visible al exterior, por tanto, no se alteraba el aspecto y carácter del monasterio. No

${ }_{13}$ Memoria de las obras y mejoras efectuadas desde 1930 a 1959, en AMS, Papeles del tiempo del abad Mauro Gómez (19301972), carpeta F10, sin foliar; ARIAS CUENLLAS, Maximino, 1992, p. 491; PORTILLA COSTA, Pedro de la, 2003, p. 50. La referencia a los nombres de los monjes que dirigían la carpintería y la herrería se encuentra en RIVERA MANSO, Francisco, 1960.

14 Informe relativo al siniestro y reconstrucción del monasterio de Samos (1951), en Instituto del Patrimonio Cultural de España (en adelante, IPCE), Archivo central, Sección de Archivo Histórico de Proyectos, sign. AHP 25/51. LÓPEZ SALAS, Estefanía, 2016, pp. 438-440.

${ }_{15}$ Memoria de las obras y mejoras efectuadas desde 1930 a 1959, en AMS, Papeles del tiempo del abad Mauro Gómez (19301972), carpeta F10, sin foliar.

${ }^{16}$ Carta de Atenas, 1931, p. 2. En: http://ipce.mcu.es/conservacion/intervencion.html (Fecha de consulta: 31-10-2013).

17 Carta de Atenas, 1931, p. 2. En: http://ipce.mcu.es/conservacion/intervencion.html (Fecha de consulta: 31-10-2013).

18 Memoria de las obras y mejoras efectuadas desde 1930 a 1959, en AMS, Papeles del tiempo del abad Mauro Gómez (19301972), carpeta F10, sin foliar. 

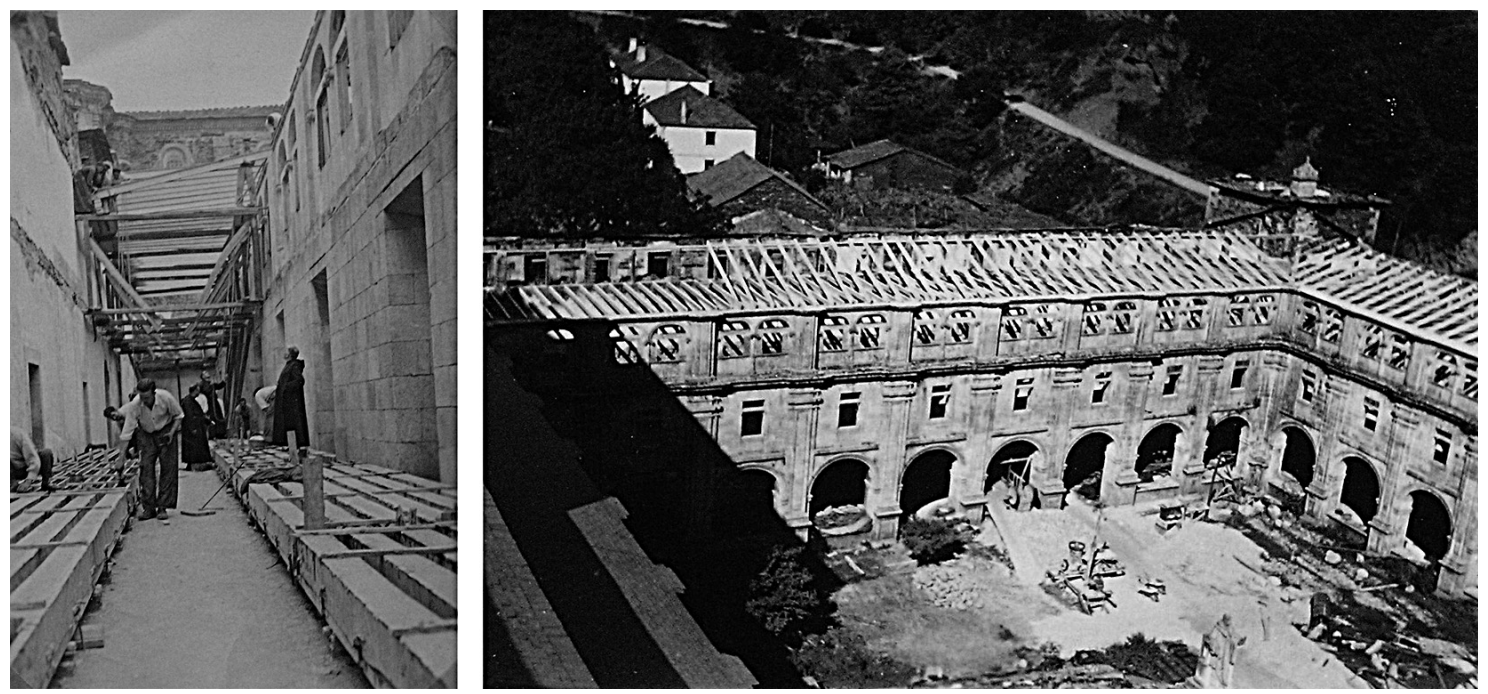

Fig. 3. El proceso de reconstrucción de las estructuras de cubierta y de los forjados situados entre la primera y la segunda planta a través de nuevas estructuras de hormigón armado, 1953-1954. (C) Fondo Fotográfico del Monasterio de San Julián de Samos.

ocurría lo mismo, sin embargo, con el material que definía la superficie exterior de las cubiertas. En este caso se usó pizarra, apostando así por el mismo material que tenían las originales, aunque con una confección y disposición de las piezas más regular.

Los forjados que actuaban de techo de la planta primera y piso de la planta segunda, se resolvieron con un sistema similar. En su reconstrucción se utilizaron "vigas de cemento armado, recubiertas, después, con madera para conservar el estilo y armonía de la construcción, cerrando los vanos intermedios con doble placa de ladrillo o bloques de hormigón". ${ }^{19}$

Desde la planta primera, las vigas de madera que conformaban el techo original de las naves, tanto en el claustro grande como en el claustro de la Nereidas, eran vistas, tal y como podemos observar en las fotografías que se conservan del interior del monasterio antes de ser destruido por el incendio. Con el fin de mantener un aspecto lo más parecido posible al del espacio existente antes de septiembre de 1951, las nuevas vigas de hormigón armado se recubrieron por su cara inferior de madera, siguiendo, de nuevo, la recomendación de la Carta de Atenas de disimular los elementos construidos con la técnica moderna para no alterar el aspecto y carácter del edificio a restaurar.
La fabricación de los nuevos elementos estructurales se llevó a cabo en el mismo monasterio, lo cual permitía reducir costes y una mayor rapidez en la ejecución de los trabajos. Los materiales necesarios, como cemento y armaduras metálicas, se acumularon en el patio del claustro grande. ${ }^{20} \mathrm{En}$ la carpintería creada por los monjes se elaboraron los moldes de madera o encofrados que eran necesarios para obtener las vigas de hormigón armado. Señala Arias Cuenllas que "se hicieron (...) más de cien moldes de madera para la fabricación de las cerca de cinco mil vigas de cemento armado, que se precisaron para los pisos y techumbre". ${ }^{21}$

A través de las fotografías tomadas durante la ejecución de las obras sabemos que los moldes de madera se dispusieron sobre el piso de la planta primera, por ser el lugar más próximo tanto a la cubierta como al forjado que era necesario reconstruir. Dentro del encofrado se introducían las armaduras de refuerzo interno, previamente conformadas $y$, en último lugar, se vertía el hormigón. Pasado el tiempo de fraguado necesario se desmontaba el molde de madera para extraer la viga ya elaborada (fig. 3).

Para reconstruir la estructura de cubierta se montaron cimbras auxiliares de madera que permitían a los albañiles y monjes disponer de un suelo provisional desde el que llevar a cabo la colocación de las vigas previamente fabricadas. Este proceso

\footnotetext{
${ }^{19}$ Memoria de las obras y mejoras efectuadas desde 1930 a 1959, en AMS, Papeles del tiempo del abad Mauro Gómez (19301972), carpeta F10, sin foliar.

20 ARIAS CUENLLAS, Maximino, 1992, p. 491.

21 ARIAS CUENLLAS, Maximino, 1992, p. 491.
} 
comenzó en agosto de 1953.22 Finalizado el montaje de las vigas de cubierta se procedió a la recuperación del forjado. Las obras de reconstrucción de estos elementos estructurales afectados por el incendio se prolongaron hasta agosto de $1955 .^{23}$ Una vez que la estructura estaba recuperada, los trabajos avanzaron de forma más rápida.

\section{Las nuevas escaleras}

El informe de daños producidos durante el incendio, redactado en octubre de 1951, señalaba que en el claustro de las Nereidas la escalera de madera de acceso a las últimas plantas había desaparecido y que las dos escaleras que poseía el claustro grande también sufrieran la destrucción total de sus tramos altos. ${ }^{24}$ Esas tres escaleras permitían el acceso desde la planta inferior del monasterio a los dos pisos superiores de ambos claustros y eso las convertía en los principales elementos de comunicación vertical.

A mayores, existían dos escaleras en el claustro grande, en el ala pegada al templo, que solamente comunicaban la primera planta de aquel con el nivel superior, de ahí su carácter secundario respecto de las tres citadas anteriormente. Por otra parte, su posición más alejada del punto de inicio del incendio, hizo que no fueran completamente destruidas por el fuego, tal y como muestran las fotografías del siniestro, aunque sí se encontraban muy dañadas y era necesaria su recuperación.

En los trabajos de reconstrucción de las escaleras se siguieron pautas muy similares a las utilizadas en la nueva estructura de cubiertas y forjados. El hormigón armado fue el material elegido para la elaboración de las vigas de soporte de las piezas de granito que definen los nuevos peldaños y mesetas. Dichos elementos estructurales quedan ocultos al exterior por sus caras laterales e inferior, tras ser revestidos con piedra del mismo tipo que la utilizada en el resto de la escalera. De esta forma se disimulaba la presencia de los elementos construidos según la técnica moderna y se conseguía un aspecto de la pieza recuperada acorde con la desaparecida y respetuosa con la naturaleza del edificio.
Las cinco escaleras del monasterio se reconstruyeron utilizando el mismo tipo de estructura y materiales, pero variaban algunos aspectos de tipo ornamental y compositivo. Las cuatro escaleras originales del claustro grande estaban formadas por dos rampas, tanto en su desarrollo entre la planta baja y primera, como entre esta última y la segunda, y ese fue el diseño mantenido durante la reconstrucción. Las dos escaleras principales del claustro grande se diferenciaban de las dos secundarias, no sólo en su mayor desarrollo en altura, sino también en que cada una de sus rampas era más ancha. En cuanto a la resolución de las barandillas, en los cuatro casos se optó por un diseño sencillo, de apariencia maciza, construido con tabiquería de ladrillo pintada de blanco y coronada, a lo largo de toda su cara superior, por un pasamanos pétreo directamente apoyado en la anterior.

El respeto al diseño original de la disposición de las rampas que sí se mantuvo en la reconstrucción de las escaleras del claustro grande, no se aplicó, sin embargo, en la recuperación de la escalera del claustro de las Nereidas. Desde antiguo, esta pieza estaba considerada como la escalera principal del monasterio y, quizás por esa razón, se puso especial empeño en llevar a cabo una reconstrucción acorde con su importancia.

La primera propuesta que se conserva en el archivo del monasterio de Samos para la Reconstrucción y reforma de la escalera principal está fechada en febrero de $1954 . .^{25}$ No fue redactada por Juan Monleón Sapiña, sino por un arquitecto madrileño Ilamado Juan Fernández Yáñez y Ozores (... - Madrid, 1 de octubre de 1979). ${ }^{26}$

De esa primera propuesta, tan sólo conservamos un dibujo en el que se representó en perspectiva el aspecto de la nueva escalera visto desde la planta primera del claustro de las Nereidas. No obstante, ese documento es suficiente para comprender cuáles eran las permanencias y cambios que se proponían con respecto a la escalera original que conocemos bien a través de varias fotografías tomadas antes de septiembre de 1951.

\footnotetext{
22 "Veintiún millones de pesetas...", 1960, p. 47; ARIAS CUENLLAS, Maximino, 1992, pp. 491-492.

23 ARIAS CUENLLAS, Maximino, 1992, p. 492.

${ }^{24}$ Informe relativo al siniestro y reconstrucción del monasterio de Samos (1951), en IPCE, Archivo central, Sección de Archivo Histórico de Proyectos, sign. AHP 25/51, fol. 2; LÓPEZ SALAS, Estefanía, 2016, pp. 437-438.

25 AMS, Dibujos de Juan Fernández Yáñez y Ozores para la reforma de las celdas y la escalera del claustro de las Nereidas, febrero de 1954. A esta propuesta hace referencia GARRIDO MORENO, Antonio, 2008, pp. 184-185.

26 ABC, 16 de octubre de 1979, p. 89. En: <http://hemeroteca.abc.es/> (Fecha de consulta: 21-7-2017). No sabemos la fecha de su nacimiento, pero sí que tituló como arquitecto en 1921. Así lo recoge SEGOVIA MARTíN, José Carlos, 2001, p. 280.
} 

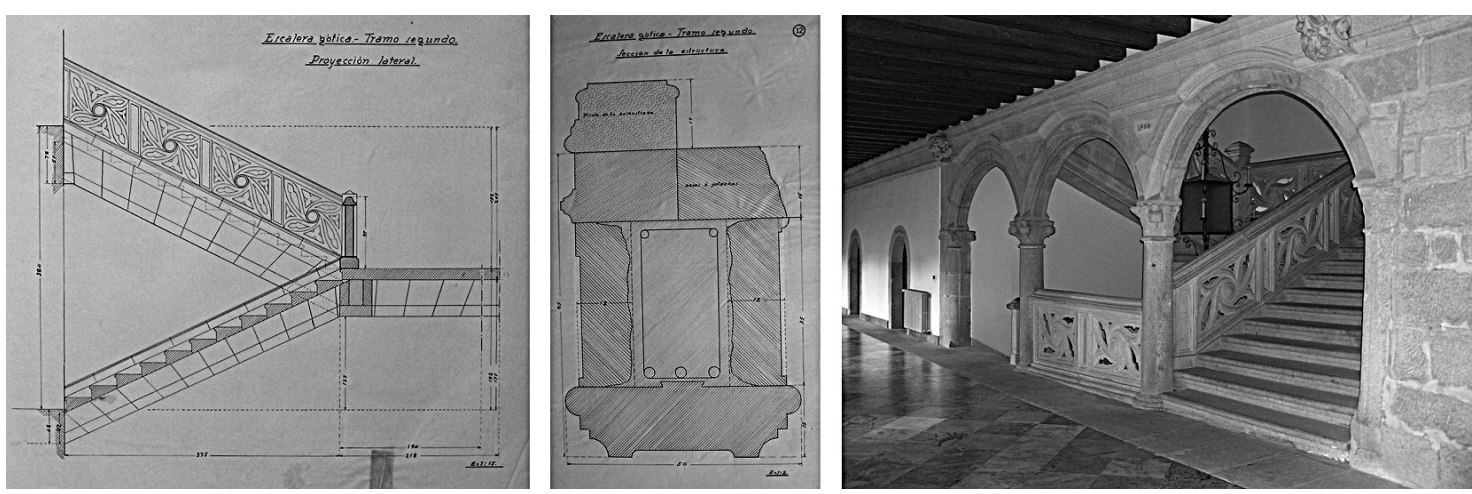

Fig. 4. Dos planos del proyecto definitivo diseñado por Juan Monleón Sapiña para la reconstrucción de la escalera del claustro de las Nereidas e imagen de su estado en la actualidad. (c) Archivo del Monasterio de San Julián de Samos y fotografía de la autora.

En primer lugar, Juan Fernández planteaba mantener la estructura original de madera, tal y como se deduce de la forma de representar las vigas horizontales e inclinadas de los extremos de las rampas, con líneas sinuosas que imitaban a las vetas de la madera, dibujadas a lo largo de sus caras vistas y que, igualmente, fueron realizadas en cada una de las piezas estructurales que definían la cara inferior de la última rampa representada.

En segundo lugar, el arquitecto proponía un cambio importante en cuanto a la disposición de las rampas, respecto de la que poseía originalmente la escalera desaparecida. Tres era el número de rampas que conformaban el desarrollo de la escalera del claustro de las Nereidas entre la planta baja y primera, que se reducían a dos en el trayecto de la planta primera a la segunda, antes del incendio de 1951. En la propuesta de reconstrucción y reforma de 1954, Juan Fernández prolongaba el desarrollo en tres rampas a lo largo de todo su recorrido, de forma que las dos rampas que poseía la escalera original entre la primera planta y la segunda eran ampliadas a tres. A consecuencia de ello, la triple arcada del primer piso a la que llegaban y de la partían las rampas de la escalera también experimentaba una modificación. Si bien en la escalera original el tercer arco se abría al hueco de la misma como balcón, en la propuesta de Juan Fernández esa función era trasladada al arco central.

En tercer y último lugar, en el dibujo de 1954 se pueden reconocer cambios en el modo de resolver las barandillas en ambos extremos del recorrido. Piezas de cantería caladas cerraban la parte inferior del arco central, mientras que una barandilla de madera, con balaustres torneados, arrancaba del primer piso y se prolongaba hasta la terminación de la escalera en la planta superior.

Aunque la propuesta de Juan Fernández Yáñez y Ozores de 1954 no fue construida, sirvió de base para el proyecto de escalera neogótica que, años más tarde, diseñó Juan Monleón Sapiña y que se convirtió en el nuevo elemento de comunicación principal del claustro de las Nereidas.

Pero antes de redactar el proyecto definitivo, Juan Monleón elaboró un anteproyecto, en agosto de 1957. ${ }^{27}$ De este primer diseño solamente se conservan los planos en planta, alzado y sección de las tres rampas correspondientes al desarrollo de la escalera entre las plantas baja y primera. En ellos se mantenía el número original de rampas, tres, de las cuales la segunda y la tercera se resolvían como estructuras abovedadas de cantería que se rellenaban por su cara superior para permitir el apoyo de los peldaños. Asimismo, se planteaba un diseño de barandilla formada por módulos de cantería calada, decorados con motivos ornamentales y que se repetían en todo su desarrollo.

En marzo de 1958, Juan Monleón redactó el proyecto definitivo para la reconstrucción de la escalera del claustro de las Nereidas (fig. 4). En él mantenía el diseño recogido en el anteproyecto anterior para las rampas del primer tramo de la escalera, realizando tan sólo un pequeño cambio en la planta de la primera de ellas. En el diseño de 1957 esta última era ligeramente curva en su arranque, mientras que en la propuesta de un año después se eliminaba esa curvatura en favor de un trazado recto, tal y como fue construida y podemos ver en la actualidad.

27 AMS, Proyecto de reconstrucción del monasterio tras el incendio de 1951, carpeta IX, planos IX-1 a IX-11. 
Por otra parte, el proyecto de 1958 incluía los planos realizados para la reconstrucción total del segundo tramo de la escalera, el situado entre la planta primera y segunda del claustro. En ellos es donde mejor se pone de manifiesto la influencia de la propuesta de Juan Fernández en el diseño de Juan Monleón. Se plantean tres rampas de escalera en continuidad con el tramo anterior. No obstante, como la distancia en altura entre las plantas baja y primera es mayor que la existente entre esta última y la segunda; frente a las tres rampas inclinadas del primer tramo, el segundo se resuelve con solo dos rampas y un rellano.

Al mismo tiempo, en el proyecto definitivo, Juan Monleón desechaba la solución de estructura de madera para las vigas de sustentación de la nueva escalera que en 1954 propusiera Juan Fernández. En su lugar, apostaba por el uso del hormigón armado, en consonancia con los otros elementos estructurales que, por aquellos años, ya se habían reconstruido en el monasterio. Entre los documentos del proyecto figuran planos en los que se dibujaron con detalle cada una de las vigas de hormigón armado que sujetan las tres rampas del segundo tramo, con sus alzados, sus secciones y el replanteo de sus armaduras internas y demás elementos de refuerzo.

Además, fueron dibujados todos y cada uno de los despieces de los revestimientos, con placas de granito de Parga, que hoy cubren las caras laterales de las vigas y la superficie inferior de las rampas. Con ellos se conseguía ocultar al exterior el aspecto del hormigón armado, disonante con la imagen tradicional del monasterio.

El resto de planos que conforman el proyecto definitivo de marzo de 1958 contienen las plantillas para la elaboración de los peldaños, los detalles en planta y alzado del arranque de la escalera en planta baja con un pilar del que carecía en su origen, perspectivas con el pasamanos, alzados de los módulos de piedra calada de la barandilla,... El último plano dibujado por Juan Monleón para la nueva escalera del claustro de las Nereidas data de julio de 1973. Recoge el alzado de la gran superficie vidriada que fue construida para cerrar el arco de ingreso a la escalera desde la planta inferior, en busca de un cierto aislamiento del espacio destinado a celdas en las plantas superiores que, hasta ese momento, estaba en comunicación directa con el patio interior.

\section{La reconstrucción de las galerías}

De este espacio del monasterio, el incendio dejó en pie tan sólo los muros de piedra que cierran las galerías de los claustros por la zona que miran al patio y aquellos otros que las separan del interior de las distintas dependencias, además de la superficie abovedada que cubre su planta baja. Todo lo demás quedó destruido o muy dañado por el fuego. Por tanto, era necesario reconstruir los pavimentos, las ventanas, las puertas..., e, incluso, reparar algunas zonas de los muros pétreos que se encontraban deterioradas.

En lo que respecta a la pavimentación, a través de diversas fotografías sabemos que, antes del incendio, las plantas baja y primera de ambos claustros estaban pisadas con piedras de granito de tamaño no homogéneo y disposición poco regular, a excepción de las que formaban las bandas continuas que definían el encuentro de la superficie de los suelos con los muros situados en ambos extremos de las galerías. De la planta segunda de ambos claustros, la no localización de fotografías fechadas antes de 1951, nos impide conocer cómo estaban construidos sus antiguos pavimentos.

El incendio destruyó por completo el pavimento de las galerías de la planta segunda, como consecuencia de la caída de los forjados correspondientes a ese nivel; dañó la superficie de los suelos de la planta primera, sobre los cuales cayeron todas las vigas que conformaban la estructura de su techo y de las cubiertas, así como el mobiliario y demás objetos que contenían las celdas del nivel superior; y, en último lugar, el incendio no destruyó los pavimentos pétreos de las galerías en planta baja, al mantenerse en pie toda la superficie abovedada que las cubría, pero los trabajos de extinción y posterior desescombro acabaron por dañarlos en algunas zonas, e hicieron necesaria su reposición.

En el archivo del monasterio de Samos tan sólo se conservan dos planos con el nuevo diseño de los pavimentos de las galerías de los claustros, uno de las Nereidas y el otro del P. Feijoo. ${ }^{28}$ En ambos casos se planteaba una subdivisión de la superficie en sucesivas áreas centrales, de planta rectangular, separadas entre sí y de la tabiquería interior, mediante bandas resueltas con un material diferente. Este modelo de nuevo pavimento tan sólo se aplicó en la resolución de las galerías de la planta baja del claustro grande, en las que cada

${ }^{28}$ AMS, Proyecto de reconstrucción del monasterio tras el incendio de 1951, carpeta I, planos I-10 y I-11. 

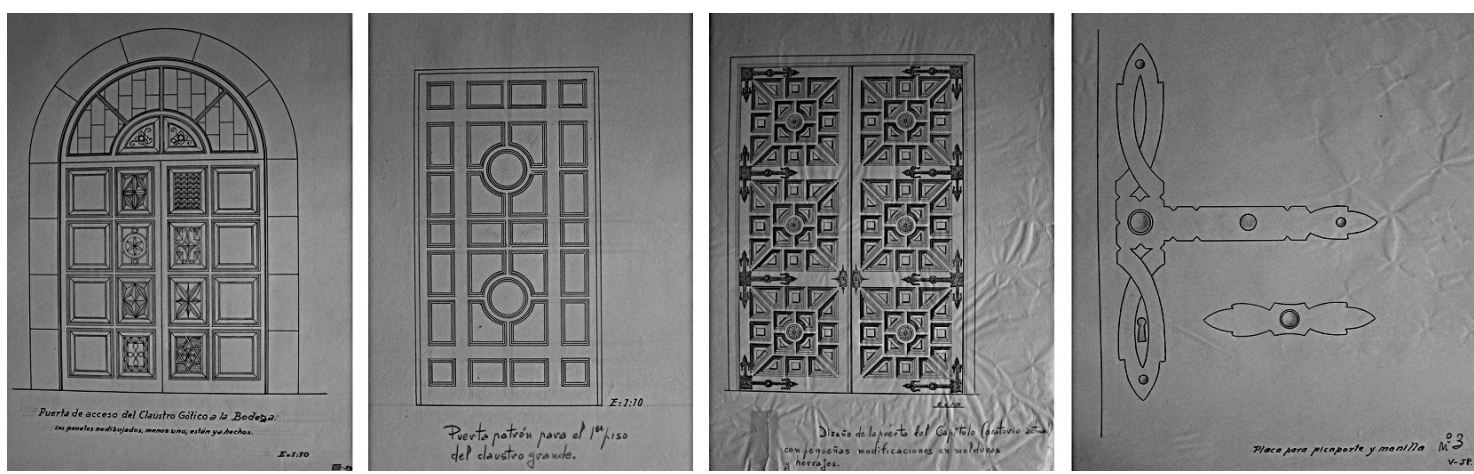

Fig. 5. Dibujos de Juan Monleón Sapińa para las nuevas puertas del monasterio. @ A Archivo del Monasterio de San Julián de Samos.

uno de los rectángulos centrales en los que fue subdivida la superficie, se reconstruyó con losas irregulares de pizarra, dispuestas de forma aleatoria, y rodeadas por todas sus caras con bandas hechas con piedra de granito.

En el caso de la planta baja del claustro de las Nereidas, el nuevo pavimento se resolvió en su totalidad con piedras de granito, respetando así la materialidad original del espacio, aunque las piezas son, en general, de tamaño homogéneo y disposición más regular -en bandas continuas paralelas a los muros-, que las del pavimento antiguo.

En la reconstrucción de los nuevos pavimentos de la planta primera de ambos claustros se utilizaron losas cuadradas de mármol, en lugar de las piedras de granito originales. Se dispusieron formando un ajedrezado en el que se alternan piezas de tono gris con otras de color blanco, dispuestas con cierta inclinación de sus caras respecto de las líneas que definen los muros extremos. La superficie ajedrezada del pavimento queda separada tanto de la tabiquería de las dependencias interiores, como de los muros exteriores, mediante bandas continuas de mármol gris, con las piezas dispuestas con sus caras paralelas a los muros, en el caso del claustro grande. En el pavimento del claustro de las Nereidas se mantuvo la superficie central ajedrezada de mármol, pero las bandas extremas se resolvieron en piedra de granito.

En la reconstrucción de los pavimentos de la plan- ta segunda de ambos claustros se utilizaron baldosas cerámicas ${ }^{29}$ de color rojo, que era el material que los arquitectos redactores del informe de octubre de 1951, habían señalado como adecuado para reponer los pavimentos dañados. ${ }^{30}$

Además de los pavimentos, el fuego destruyó la mayor parte de la carpintería original del monasterio. En total, el informe de daños redactado en 1951 contabilizaba "doscientas sesenta ventanas, doscientas puertas de paso, ciento veinte ventanales metálicos y siete grandes puertas principales", ${ }^{31}$ que era necesario reconstruir. Según $L a$ Vanguardia Española, en 25 de septiembre de 1954 ya se hallaban "preparados 170 metros cúbicos de madera de castaño para ser empleados en ventanas, puertas y artesonados". ${ }^{32}$

La falta de modulación de la carpintería obligó a Juan Monleón a dibujar las nuevas ventanas, puertas y vidrieras, así como todos los herrajes necesarios (fig. 5). De su construcción se ocuparon los talleres de carpintería y cerrajería instalados en el monasterio. De la planta baja del claustro de las Nereidas se conservan los planos elaborados para cuatro nuevas puertas de madera de las siete existentes. Se trata de la nueva puerta románica dibujada en noviembre de 1958, la nueva puerta de acceso a la cocina desde las galerías del claustro y algunos bocetos para la puerta de la biblioteca, ambas fechadas en julio de 1959, y, por último, la puerta de acceso a la bodega, de agosto de $1959 .{ }^{33}$

${ }^{29}$ Memoria de las obras y mejoras efectuadas desde 1930 a 1959, en AMS, Papeles del tiempo del abad Mauro Gómez (19301972), carpeta F10, sin foliar; ARIAS CUENLLAS, Maximino, 1992, p. 492.

30 Informe relativo al siniestro y reconstrucción del monasterio de Samos (1951), en IPCE, Archivo central, Sección de Archivo Histórico de Proyectos, sign. AHP 25/51, fol. 3; LÓPEZ SALAS, Estefanía, 2016, pp. 438.

31 Informe relativo al siniestro y reconstrucción del monasterio de Samos (1951), en IPCE, Archivo central, Sección de Archivo Histórico de Proyectos, sign. AHP 25/51, fol. 3; LÓPEZ SALAS, Estefanía, 2016, p. 440.

32 "La reconstrucción del...", 1954, p. 1.

${ }_{33}$ AMS, Proyecto de reconstrucción del monasterio tras el incendio de 1951, carpeta XIV, planos XIV-1, XIV-2, XIV-3 y XIV-10. 
De la planta baja del claustro grande tan sólo se conserva el diseño elaborado para la reconstrucción de la puerta de los carros, de noviembre de 1959, ${ }^{34}$ aunque, evidentemente, también fueron reconstruidas la mayor parte de las antiguas puertas que daban acceso a las diferentes dependencias que se abrían a las galerías, algunas de las cuales fueran las primeras en ser destruidas por las llamas debido a su proximidad a la fábrica de licor, punto de origen del incendio.

Años más tarde, en octubre de 1963, se cerraron los huecos correspondientes a los dos núcleos de escaleras del claustro grande, mediante puertas de perfiles metálicos y superficies vidriadas, ${ }^{35}$ siguiendo una solución similar a la que, en julio de 1973, se empleó para cerrar el gran arco de entrada a la escalera del claustro de las Nereidas desde su planta baja. Estas actuaciones buscaban romper el contacto directo que, tradicionalmente, existiera entre el ámbito de los patios y el espacio de las celdas y otras dependencias situadas en los dos niveles superiores, que impedía un aislamiento térmico adecuado para un espacio habitado.

Para las plantas primera y segunda del claustro de las Nereidas, Juan Monleón diseñó un único modelo de puerta de madera que se utilizó para, por repetición, reconstruir los accesos a las distintas dependencias, en su mayoría celdas. En su ejecución, tan sólo variaron algunas medidas o el diseño de las molduras que, en ciertas ocasiones, fueron parcialmente sustituidas por vidrieras ubicadas en la mitad superior de las hojas de las puertas. $^{36}$

Algo similar se llevó a cabo en los pisos altos del claustro grande. A través de una puerta patrón se resolvió el acceso a la mayor parte de las dependencias. ${ }^{37}$ Tan sólo se diseñaron modelos específicos para la entrada a aquellos espacios que estaban destinados a cumplir una función singular dentro del monasterio, como la sala capitular, el noviciado, la escalera del coro alto..., y también para los huecos que ponían en comunicación las galerías de ambos claustros. ${ }^{38}$

Con respecto a las ventanas situadas en los paños de las galerías que se abren a los patios centrales, las fotografías que se conservan del estado del monasterio tras el incendio de 1951 muestran la total destrucción de las ubicadas en la planta segunda del claustro de las Nereidas y la pérdida parcial tanto de las de la planta primera de ambos claustros, como de las del piso segundo del claustro grande. El informe de daños de 1951 recomendaba la reposición de "las carpinterías de castaño de huecos interiores y exteriores manteniendo los tipos tradicionales de la región". ${ }^{39}$ No obstante, en la reconstrucción de los ventanales se pueden reconocer cambios importantes respecto de los existentes antes del incendio, que afectaron, sobre todo, a su diseño.

Comenzando por el claustro de las Nereidas, Juan Monleón dibujó en planta, alzado y sección, un modelo de carpintería exterior, en madera de castaño, para resolver las dobles ventanas adinteladas de los entrepaños de las fachadas interiores. ${ }^{40}$ A su vez, cada una de ellas está formada por dos hojas practicables que se abren mediante bisagras hacia el interior de las galerías, mientras que las ventanas existentes antes del incendio eran de guillotina. Asimismo, cada una de las hojas se subdividió en diez cuarterones, frente a los cuatro que caracterizaban las antiguas carpinterías.

Para cada uno de los óculos elipsoidales que definen los montantes o tragaluces de la parte superior de cada ventana se desechó el uso de la madera en favor de una carpintería metálica, no practicable, construida con delgados perfiles que definen, tanto los bastidores, como los peinazos que dividen cada óculo en ocho paneles menores, frente a los dos que tenían estos tragaluces antes del incendio.

\footnotetext{
${ }^{34}$ AMS, Proyecto de reconstrucción del monasterio tras el incendio de 1951, carpeta XIV, plano XIV-22.

35 AMS, Proyecto de reconstrucción del monasterio tras el incendio de 1951, carpeta XIV, planos XIV-23 y XIV-24.

${ }^{36}$ No se conserva el plano de la puerta patrón diseñada por Juan Monleón para las plantas primera y segunda del claustro de las Nereidas, sólo el dibujo de la sección de cómo debía ejecutarse el ensamblaje entre los montantes y las hojas. AMS, Proyecto de reconstrucción del monasterio tras el incendio de 1951, carpeta XIV, plano XIV-12.

37 Se conserva un plano de la puerta patrón para el primer piso del claustro grande. AMS, Proyecto de reconstrucción del monasterio tras el incendio de 1951, carpeta XIV, plano XIV-8.

${ }^{38}$ Se conservan los planos de la nueva puerta para la sala capitular, de la escalera del coro alto y de la puerta de acceso al noviciado, las dos últimas fechadas en mayo de 1958. AMS, Proyecto de reconstrucción del monasterio tras el incendio de 1951, carpeta XIV, planos XIV-11, XIV-7 y XIV-4, respectivamente.

39 Informe relativo al siniestro y reconstrucción del monasterio de Samos (1951), en IPCE, Archivo central, Sección de Archivo Histórico de Proyectos, sign. AHP 25/51, fol. 3; LÓPEZ SALAS, Estefanía, 2016, p. 440.

40 AMS, Proyecto de reconstrucción del monasterio tras el incendio de 1951, carpeta XIV, plano XIV-28.
} 
Una solución similar a la anterior se utilizó para la ejecución de las nuevas ventanas de las galerías de la primera planta del claustro grande. Las forman dobles hojas practicables, de apertura hacia el exterior, resueltas en carpintería de madera de castaño y vidrieras subdivididas en doce cuarterones por cada hoja. De esta forma se mantenía tanto la materialidad, como la forma de apertura de las antiguas ventanas, aumentando sólo el número original de elementos en las que estaban subdivididas. En cuanto a los montantes rectangulares superiores, de nuevo fueron resueltos con carpintería metálica, de delgados perfiles y mayor número de cuarterones.

Pero, sin lugar a dudas, el cambio más destacado en el proceso de reconstrucción de las ventanas de las fachadas interiores se produjo en la segunda planta de ambos claustros. Antes del incendio, dobles ventanas se abrían entre cada dos contrafuertes en el nivel superior del claustro de las Nereidas, separadas por una pilastra intermedia de la que arrancaba una columnilla de orden jónico que terminaba en la cornisa de remate de la fachada. Cada ventana se situaba sobre un antepecho sencillo y bajo un arco, ambos de cantería, que enmarcaban un espacio dentro del cual se abría una carpintería rectangular de guillotina separada, tanto de la columna central, como del contrafuerte extremo, por una superficie ciega, y coronada por un montante superior semicircular. Algo similar ocurría en la segunda planta del claustro grande, con la diferencia de que las ventanas que miraban al patio no eran de guillotina, sino de doble hoja practicable hacia el interior.

Juan Monleón diseñó los modelos de las nuevas ventanas del segundo piso, uno para las del claustro de las Nereidas y otro para el claustro grande, ambas metálicas. ${ }^{41}$ En lugar de respetar el diseño original, propuso una solución con la que las nuevas ventanas ocupaban todo el espacio delimitado por los antepechos inferiores, los arcos superiores, las columnillas intermedias y los contrafuertes o las pilastras extremas. De esta forma se conseguía introducir mayor cantidad de luz al espacio interior de las galerías, pues aumentaba la superficie de vidrio y se aligeraban considerablemente las dimensiones de los bastidores y peinazos. ${ }^{42}$
Por otra parte, en cada una de las cuatro fachadas de la segunda planta del claustro grande, los antepechos macizos en los que se apoyaban las dos ventanas que ocupan el paño central de cada ala, fueron sustituidos por balaustradas de piedra, con carpintería metálica y vidrio como elemento de cierre hacia el interior, que buscan enfatizar la centralidad de esos paños y que eran elementos inexistentes en el monasterio antes del incendio de 1951.

\section{Las nuevas celdas}

El paso final del proceso de reconstrucción del monasterio se centró en volver a hacer habitables las diferentes dependencias que antiguamente lo formaban. En general, se optó por mantener una situación lo más similar posible a la de las preexistentes, tal y como reflejan los planos de planta baja, primera y segunda del proyecto de Juan Monleón, aunque dotándolas de unas instalaciones mejores, con las que se pretendía incrementar la calidad de vida de la comunidad.

Entre las diferentes estancias que tenía el monasterio, una destacaba sobre las demás, por ser la que más se repetía y la que ocupaba una mayor superficie dentro del conjunto: la celda individual. Poco sabemos de cómo eran estas dependencias antes del incendio, al carecer de fotografías de su interior y de otro tipo de documentos que recojan algún dato sobre su anterior configuración.

La primera propuesta que se conserva en el archivo del monasterio de Samos para reconstruir las celdas, completamente destruidas por el incendio, data de febrero de $1954 .{ }^{43}$ Fue redactada por el arquitecto madrileño Juan Fernández Yáñez y Ozores y de ella tan sólo conservamos dos documentos, con el dibujo de dos posibles plantas y sus correspondientes perspectivas del interior de las nuevas celdas proyectadas.

La organización de su espacio se caracterizaba por la claridad, sencillez y funcionalidad de la distribución, agrupando los elementos más privados de las celdas hacia uno de los tabiques transversales a los gruesos muros de piedra que las separaban de las galerías de los claustros y reservando la mayor parte del espacio para zona de estudio, lectura o rezo individual. Como elemento nuevo se in-

41 AMS, Proyecto de reconstrucción del monasterio tras el incendio de 1951, carpeta XIV, plano XIV-13.

42 La variabilidad en la forma y dimensiones de las nuevas ventanas, especialmente de las correspondientes a la segunda planta del claustro de las Nereidas, obligó a "situar ante cada ventana una fragua para construir los bastidores, todos ellos de hierro, a medida exacta de cada hueco". RIVERA MANSO, Francisco, 1960.

43 AMS, Dibujos de Juan Fernández Yáñez y Ozores para la reforma de las celdas y la escalera del claustro de las Nereidas, febrero de 1954 
troducía el cuarto de aseo, con baño, ducha, lavabo e inodoro, directamente comunicado con el exterior a través de una de las dos ventanas de las que disponía cada celda, lo que permitía su iluminación y ventilación.

Aunque esa no fue la solución construida, sí influyó en el proyecto de nueva celda que planteó, posiblemente algunos años más tarde, Juan Monleón. ${ }^{44}$ En esta segunda propuesta se mantenía la idea principal de la anterior y tan sólo se variaban las dimensiones en anchura de los espacios destinados a dormitorio y cuarto de aseo, sugiriendo entre ambos, dos pequeños ámbitos reservados a armarios de fábrica.

Siguiendo este planteamiento fueron reconstruidas parte de las celdas individuales ubicadas en el claustro de las Nereidas, doce en la planta prime$\mathrm{ra}^{45}$ y cuatro en la planta segunda. El resto, tres en la planta primera y dieciséis en la segunda, no fueron dotadas de cuartos individuales, y para ellas se construyeron tres estancias con la función de baños comunes, dos en la planta primera y una en la segunda. Así lo reflejan los planos de estado actual de distribución de las plantas primera y segunda, elaborados por el arquitecto Antonio González Trigo, para las obras de mejora y conservación de la abadía, de noviembre de 1999. ${ }^{46} \mathrm{La}$ única diferencia entre la realidad construida y lo planteado por Juan Monleón radicaba en que el dormitorio no fue separado mediante un tabique del espacio de la celda destinado a lectura, estudio y oración.

En las obras de reconstrucción de las celdas se emplearon nuevos pavimentos de madera y tabiquerías de ladrillo revocadas y pintadas de blanco. De igual forma, fue necesario hacer de nuevo todo el mobiliario interior y las ventanas, de las más diversas formas y tamaños, que permitían la iluminación de estos espacios a través de los muros exteriores del monasterio.

Además de las celdas de los monjes reconstruidas en el claustro de las Nereidas, se hicieron de nue- vo las celdas de la hospedería, cuatro en la planta primera del claustro grande y once en la segunda, en ambos casos situadas en el ala sureste, la que mira al río. Las quince celdas fueron pavimentadas con madera y se las dotó de lavabos de agua corriente y del mobiliario necesario. ${ }^{47}$ Carecen de cuartos de aseos individuales y, en su lugar, se construyó un baño común por planta destinado a los huéspedes.

Asimismo, en el ala noreste de la planta segunda del claustro grande se reconstruyó el colegio monacal, en el mismo lugar en el que estaba antes del incendio, aunque trasladando las aulas de la galería pegada a la iglesia, al ala correspondiente a los dormitorios y aseos. Señala Arias Cuenllas que se amplió su capacidad a 50 alumnos y que fue dotado de "aulas, salón de estudio, dormitorio y cuarto de aseo, con agua corriente en las instalaciones de lavabos, duchas, inodoros y demás servicios sanitarios". ${ }^{48}$

Pero el cambio más destacado en la reconstrucción de las celdas se produjo en las alas noroeste y suroeste de la segunda planta del claustro grande, donde fueron ubicadas veintiocho nuevas celdas individuales para novicios, inexistentes en el monasterio antes del incendio de 1951. Para ellas se diseñó una nueva distribución del espacio que recoge el plano de la planta segunda del proyecto de reconstrucción de Juan Monleón. Las nuevas celdas se dispusieron pegadas a los ventanales que miran al patio, dejando un estrecho pasillo interior que permite el acceso a todas ellas y a los núcleos de escaleras que comunican esta planta con la inferior y con los torreones superiores. Del nuevo noviciado señala Arias Cuenllas que sus celdas fueron provistas de "lavabos con agua corriente, y con dispositivo para la calefacción eléctrica (...) un cuarto de aseo, con agua corriente, caliente y fría, en baños, duchas, lavabos y demás servicios; y asimismo de aulas propias en el torreón norte, y oratorio particular independiente". ${ }^{49}$

\footnotetext{
${ }^{44}$ AMS, Proyecto de reconstrucción del monasterio tras el incendio de 1951, carpeta I, plano I-14, sin fechar.

${ }^{45}$ No contabilizamos la celda destinada al abad que, por su mayor dimensión, respondía a una distribución diferente.

${ }_{46}$ AMS, Obras de mejora y conservación de la abadía de Samos, noviembre de 1999, arquitecto Antonio González Trigo, planos $n^{\circ} 8$ y 9.

47 ARIAS CUENLLAS, Maximino, 1992, p. 492; PORTILLA COSTA, Pedro de la, 2003, p. 52.

48 AMS, Papeles del tiempo del abad Mauro Gómez (1930-1972), carpeta F10, sin foliar; ARIAS CUENLLAS, Maximino, 1992, p. 492; PORTILLA COSTA, Pedro de la, 2003, p. 52.

49 AMS, Papeles del tiempo del abad Mauro Gómez (1930-1972), carpeta F10, Sin foliar; ARIAS CUENLLAS, Maximino, 1992, p. 492; PORTILLA COSTA, Pedro de la, 2003, p. 52.
} 


\section{La nueva sala capitular y el nuevo salón del piano}

En la primera planta del claustro grande, en el ala noroeste, inmediata al signo $\mathrm{y}$, por tanto, muy próxima al templo, se situaba, desde principios del siglo XVIII, el espacio destinado a sala capitular del monasterio, un lugar para oír los consejos y advertencias del abad, para corregir las faltas y para tratar todo tipo de asuntos que afectaban al conjunto de la comunidad.

La función original de este espacio se mantuvo hasta el año 1854 cuando, coincidiendo con el periodo de la exclaustración, fue transformado en escuela pública de la villa. Con esa finalidad se utilizó hasta finales del año 1940, momento en el que la comunidad recuperó la antigua sala capitular mediante su compra al Ayuntamiento.

Es probable que, tanto en 1854, como en 1940, este espacio fuese sometido a procesos de reforma, primero para adaptarlo a las necesidades de una escuela y, posteriormente, para recuperar su función primigenia. De la segunda actuación tenemos constancia a través de la "Memoria de obras y mejoras efectuadas en el monasterio de Samos entre 1930 y 1951" que se conserva en el archivo del monasterio, en la que se señala que, tras la compra de esta dependencia al Ayuntamiento, la comunidad procedió a la "construcción de la correspondiente sala capitular de la comunidad".50

A través de las fotografías que se conservan del interior de este espacio, antes del incendio de 1951, sabemos que era una estancia de planta rectangular, con el punto de entrada desde el extremo de ella más próximo al signo. Triples arcadas enmarcaban el espacio del acceso, por ambos lados $y$, posiblemente, eran resultado de la actuación de reforma de los años cuarenta del siglo XX, pero no pertenecían a la sala capitular original. Interiormente contaba con dobles filas de asientos pegadas a los lados largos de la estancia, destinadas a los monjes de la comunidad y, al fondo, se situaba el sillón del abad, en una posición ligeramente sobre-elevada respecto del resto del pa- vimento de madera que definía el suelo de la sala. Vigas de madera vista conformaban la estructura del techo en continuidad con las de las galerías de los claustros.

Durante el incendio de septiembre de 1951, el local fue completamente destruido por las llamas, tal y como muestran, de forma muy clara, las fotografías tomadas en los momentos inmediatamente posteriores al siniestro. Para su reconstrucción, Juan Monleón dibujó la planta y los alzados interiores de los muros de la nueva sala, de dimensión longitudinal algo menor respecto de la original. ${ }^{51}$ Asimismo, en junio de 1959, diseñó los nuevos zócalos de madera que, con una altura de $87 \mathrm{~cm}$, recorren todo el perímetro de sus muros y que no había en la estancia preexistente. ${ }^{52}$ Igualmente, elaboró el alzado del nuevo testero que habría de situarse tras el sillón del abad, en sustitución de una desaparecida pintura mural. ${ }^{53}$

Además de todo lo anterior, se construyó un nuevo pavimento de parqué y se trató de recuperar la imagen original de los techos, recorridos por vigas de madera, apoyadas en ambos extremos en ménsulas del mismo material. Para ello la nueva estructura de vigas de hormigón armado, situadas a mucha más distancia entre sí que las originales, se recubrieron por sus caras vistas con tablones de madera, al igual que en las galerías de los claustros, tal y como reflejan los planos elaborados por Juan Monleón, reconstruyendo, asimismo, las ménsulas de apoyo extremas. ${ }^{54}$

Desde abril de 1981, la sala capitular reconstruida tras el incendio fue transformada en oratorio de la comunidad, en sustitución de otro que, de forma provisional, se había instalado en una estancia ubicada en el segundo piso del monasterio, entre los dos claustros. ${ }^{55}$ Como consecuencia de ese cambio de función, esta dependencia experimentó una nueva reforma de la que deriva, en buena medida, su imagen actual.

También en la planta primera del claustro grande, pero en el ala sureste, se ubicaba la antigua cámara abacial, justo encima de la fábrica de licor.

\footnotetext{
50 Memoria de las obras y mejoras efectuadas desde 1930 a 1959, en AMS, Papeles del tiempo del abad Mauro Gómez (19301972), carpeta F10, sin foliar.

51 AMS, Proyecto de reconstrucción del monasterio tras el incendio de 1951, carpeta IV, plano IV-6.

52 AMS, Proyecto de reconstrucción del monasterio tras el incendio de 1951, carpeta IV, plano IV-8.

53 AMS, Proyecto de reconstrucción del monasterio tras el incendio de 1951, carpeta IV, plano IV-7.

54 AMS, Proyecto de reconstrucción del monasterio tras el incendio de 1951, carpeta IV, planos IV-9, I-10.

55 Así lo reflejan los planos de Antonio González Trigo, elaborados para las obras de mejora y conservación de 1999; aunque Arias Cuenllas señala que se ubicaba en la primera planta, ARIAS CUENLLAS, Maximino, 1992, p. 514
} 
Aunque era la dependencia destinada en origen a celda del abad, no cumplía esa función en el momento de producirse el incendio que provocó su destrucción. Sólo quedaron en pie los gruesos muros pétreos que la delimitaban y la gran chimenea que existía en su interior, con sus sillares algo erosionados por las llamas. ${ }^{56}$

Al igual que en el caso de la sala capitular, Juan Monleón dibujó el plano de la planta y los alzados de los muros interiores de la antigua cámara abacial, con el objetivo de llevar a cabo su reconstrucción ${ }^{57}$ y elaboró un plano en alzado para recuperar algunas partes dañadas de la chimenea..$^{58}$ Tras el incendio, varias son las denominaciones que recibe esta estancia en la documentación consultada, sala del piano, sala de conferencias, salón de huéspedes o salón de lectura, pero ya no volvió a emplearse el término de cámara del abad, función que se trasladó, definitivamente, a una de las celdas reconstruidas en la primera planta del claustro de las Nereidas.

\section{La rehabilitación del refectorio y la nueva cocina monacal}

Poca documentación escrita y gráfica conservamos sobre el estado en el que, tras el incendio, se encontraban las dependencias del ala suroeste de la planta baja del claustro de las Nereidas, es decir, el refectorio de la comunidad, las cocinas y el refectorio de los criados. ${ }^{59}$ El informe de daños de 1951 señalaba que la destrucción de los forjados en la planta primera de dicho claustro afectara a todas las zonas no abovedadas, lo cual incluía "la crujía exterior de las salas del mediodía, norte y parte de la de poniente no ocupada por el refectorio". ${ }^{60}$ Más adelante, entre los trabajos de restauración a realizar, los redactores de este informe indicaban la necesidad de consolidar las bóvedas del refectorio. ${ }^{61}$

A nivel gráfico tenemos constancia de la destrucción de las dependencias situadas en las plantas inmediatamente superiores al área citada, pero no se conservan fotografías del interior de los refectorios o de las cocinas tras el incendio. Tan sólo contamos con una imagen realizada en los días posteriores, en la que se muestra el aspecto exterior del ala suroeste del claustro. En ella es posible reconocer los cambios que, tan sólo algunos años atrás, se habían ejecutado en el exterior del refectorio de los monjes. ${ }^{62}$

Pero quizás lo más destacado de esa fotografía es que a través de ella descubrimos la ausencia de los masivos contrafuertes que, desde antiguo, caracterizaban la fachada suroeste de este claustro. Esto nos lleva a pensar que, antes de que el siniestro tuviese lugar, los monjes decidieron derribar los contrafuertes originales, de distribución y tamaño irregulares, para proceder a su sustitución por otros nuevos, dispuestos a distancias regulares y construidos respondiendo a un mismo diseño.

Juan Monleón fue el encargado tanto de rehabilitar el espacio interior del refectorio, donde el fuego posiblemente dañó parte del mobiliario y algunas de las vidrieras, como de afrontar el diseño y ejecución de los nuevos contrafuertes. Entre los planos conservados en el archivo del monasterio de Samos del proceso de reconstrucción figuran: una planta del refectorio, el despiece de la cantería necesaria para construir una nueva ventana, el alzado lateral y frontal del modelo de nuevo contrafuerte -de abril de 1956- y algunos diseños del nuevo mobiliario interior. ${ }^{63}$

Asimismo, Juan Monleón elaboró los dibujos para la reforma de las dependencias que, en el plano de Miguel Durán, se correspondían con las dos cocinas y el refectorio de los criados, situadas al norte del refectorio de los monjes. Esos tres ámbitos se unieron en un único espacio destinado a nueva cocina monacal, más amplia que las preexistentes y con modernas instalaciones. Para su rehabilitación Juan Monleón diseñó un total de cuatro proyectos, en los que ensayaba diferentes organizaciones del espacio. ${ }^{64}$ De ellos, el primero, fechado

\footnotetext{
56 "La gloriosa abadía...", 1960, p. 5.

57 AMS, Proyecto de reconstrucción del monasterio tras el incendio de 1951, carpeta IV, plano IV-11.

58 AMS, Proyecto de reconstrucción del monasterio tras el incendio de 1951, carpeta XII, plano XII-9.

59 Son las dependencias que se señalan en el plano publicado por DURÁN, Miguel, 1947, Fig. I.

60 Informe relativo al siniestro y reconstrucción del monasterio de Samos (1951), en IPCE, Archivo central, Sección de Archivo Histórico de Proyectos, sign. AHP 25/51, fol. 2; LÓPEZ SALAS, Estefanía, 2016, p. 437.

61 Informe relativo al siniestro y reconstrucción del monasterio de Samos (1951), en IPCE, Archivo central, Sección de Archivo Histórico de Proyectos, sign. AHP 25/51, fol. 4; LÓPEZ SALAS, Estefanía, 2016, p. 440

62 Nos referimos a las nuevas ventanas abiertas en esta dependencia durante la reforma de 1940.

63 AMS, Proyecto de reconstrucción del monasterio tras el incendio de 1951, carpeta X, planos X-6, X-8 y X-9.

64 AMS, Proyecto de reconstrucción del monasterio tras el incendio de 1951, carpeta XVI, planos XVI-7, XVI-8 y XVI-9.
} 
en abril de 1959, es el que más se asimila al finalmente construido que, con pequeños cambios, es el que se mantiene en la actualidad.

\section{La nueva plaza de la iglesia y la ampliación del tramo de carretera inmediato al monasterio}

Tras el incendio, la última actuación de lo que entendemos como primera fase del proceso de reconstrucción del monasterio, afectó a un espacio exterior, la llamada plaza de la iglesia. Limitada por la carretera de Sarria a Pedrafita del Cebreiro por el noroeste y por la fachada principal de la iglesia y los claustros por el noreste y sureste, este siempre fue un ámbito de paso obligado tanto para acceder al interior del templo como del monasterio.

Desde la construcción de la nueva carretera de Sarria a Pedrafita del Cebreiro entre finales del siglo XIX y principios del XX, el ámbito de la plaza estaba delimitado por un muro que, siguiendo el trazado de esa vía, cerraba el espacio público y contenía la diferencia de nivel existente entre él y la calzada. El acceso a la plaza tenía lugar a través de una portada metálica ubicada a medio camino entre la fachada de la iglesia y el pabellón del monasterio que toca la carretera. Desde ahí una escalera bajaba hasta los senderos de tierra que, en medio de las zonas ajardinadas, conducían uno hasta la escalinata de la iglesia y el otro hasta la portería del monasterio.

La idea de reformar la plaza existente estaba muy vinculada al proyecto de ensanche del tramo de carretera que rodea el monasterio, redactado por el ingeniero Ángel Cano Vega, en abril de $1957 .{ }^{65}$ A través de la memoria de este documento sabemos que, en mayo de 1956, el Ayuntamiento de Samos dirigió una instancia al Ministro de Obras Públicas en la que exponía la necesidad de ensanchar la carretera de Sarria a Pedrafita del Cebreiro a su paso por Samos, en los hectómetros 1 y 2 del kilómetro 14. Con fecha de junio de 1956, la Dirección General de Carreteras y Caminos Vecinales autorizaba a redactar el proyecto correspondiente.
Del tramo en el que se solicitaba el ensanche se decía en la memoria del proyecto que "tiene el firme de hormigón de seis metros de ancho entre aristas exteriores de bordillos, siendo su paso muy angosto en la proximidad del Monasterio de Samos, sitio que es muy frecuentado no solamente por el tráfico ordinario de por sí muy intenso, sino por las frecuentes visitas de turistas y peregrinos, no sólo nacionales, sino que también extranjeros, que se encuentran con muchas dificultades para estacionar los vehículos y para los cruces, por falta de espacio".66

Por otra parte, el ingeniero redactor señalaba que la ampliación era importante si se tenía en cuenta la próxima inauguración del monasterio reconstruido, acto para el que se preveía una aglomeración grande de vehículos y para ellos se necesitaba una superficie suficiente de aparcamiento. Para conseguir el objetivo planteado, en el proyecto de ensanche se proponía ampliar el ancho del trazado unos cuatro metros, con un afirmado de hormigón igual al que tenía la travesía ya construida. ${ }^{67}$

Poco tiempo después de que la Dirección General de Carreteras y Caminos Vecinales autorizara la redacción del proyecto de ensanche, Juan Monleón empezó a pensar en cómo debería ser el trazado de la nueva plaza (fig. 6). Dibujó un total de ocho soluciones, la primera de ellas en julio de 1956. ${ }^{68}$ De unas a otras variaba el tipo de escalera de bajada, su posición, los nuevos caminos,...

Al igual que en el caso del ensanche de la carretera, detrás de la reforma de la plaza existente es posible reconocer la intención de disponer de un espacio de acceso al templo y al monasterio más adecuado para recibir a todas aquellas autoridades que, en el día de la inauguración del monasterio, acudirían a Samos. Asimismo, la ejecución de esta obra respondía a la necesidad de poner fin a los problemas de tránsito y evacuación de las aguas que tenían lugar por causa del importante desnivel que existía con respecto a la vía. El espacio carecía de zonas pavimentadas, dificultando el acceso al monasterio y al templo parroquial cuando las Iluvias convertían la tierra en barro.

\footnotetext{
65 Archivo Histórico Provincial de Lugo (en adelante, AHPLu), Proyecto de ensanche de la carretera en su paso por Samos Hectómetros 1 y 2 - km 14, ingeniero D. Ángel Cano Vega, 1957, Fondo obras públicas, sign. 32856/2.

${ }^{66}$ AHPLu, Proyecto de ensanche de la carretera en su paso por Samos Hectómetros 1 y 2 - km 14, ingeniero D. Ángel Cano Vega, 1957, Fondo obras públicas, sign. 32856/2, fols. 1-2.

${ }^{67}$ AHPLu, Proyecto de ensanche de la carretera en su paso por Samos Hectómetros 1 y 2 - km 14, ingeniero D. Ángel Cano Vega, 1957, Fondo obras públicas, sign. 32856/2, fol. 2.

68 AMS, Proyecto de reconstrucción del monasterio tras el incendio de 1951, carpeta VII. Sobre la reforma de la plaza de la iglesia, GARRIDO MORENO, Antonio, 2008, pp. 183-184.
} 


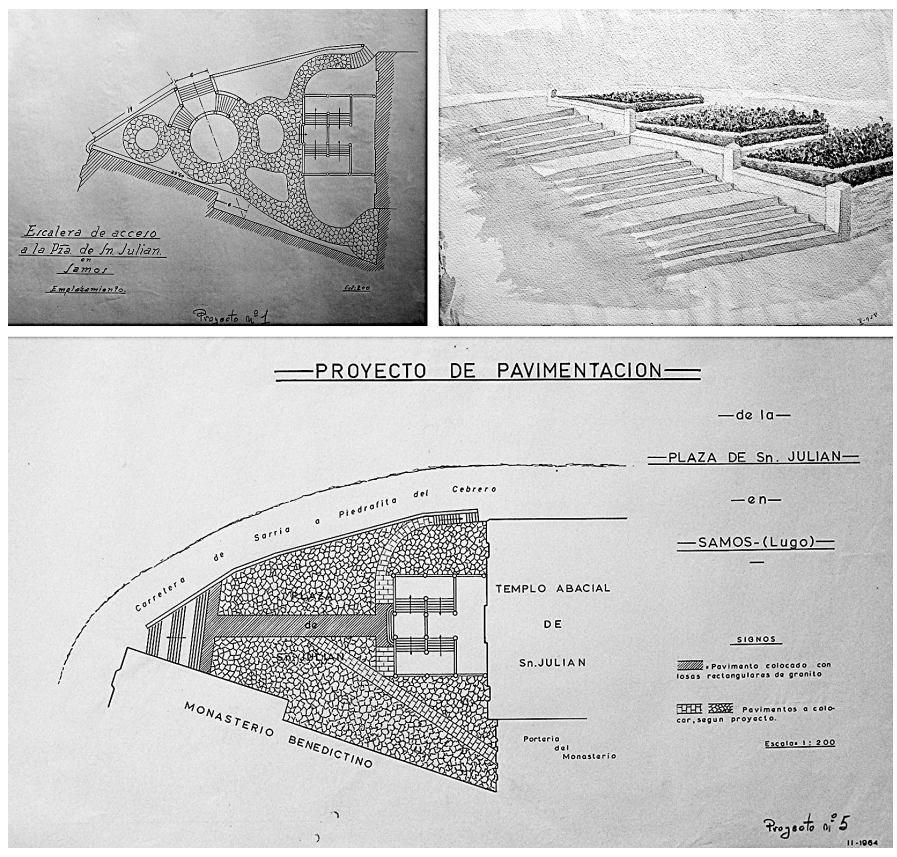

Fig. 6. Algunas propuestas y proyecto definitivo de Juan Monleón Sapiña para la reforma de la plaza de la iglesia. (c) Archivo del Monasterio de San Julián de Samos.

La primera decisión de Juan Monleón para la reforma de la plaza fue la de rebajar su suelo. Desconocemos la razón que le llevó a hacerlo, pero, posiblemente, fue la intención de descubrir la parte inferior de las fachadas del templo y del monasterio que, en esa época, se encontraban ocultas bajo la tierra. Una comparación entre las fotografías conservadas de los estados anterior y posterior a la reforma de la plaza nos permite reconocer, fácilmente, el área descubierta: todo el basamento de la iglesia y su escalinata, así como la parte baja de la fachada de la portería y de los muros del ala noroeste del claustro de las Nereidas.

Otra consecuencia del rebaje efectuado es que, hasta ese momento, el acceso a la escalinata del templo desde la plaza tenía lugar a través de dos peldaños que, tras bajar la superficie horizontal del terreno, se aumentaron a cinco, posiblemente ya existentes en el estado original.

De las ocho propuestas planteadas por Juan Monleón, finalmente, se optó por la número cinco. En ella se disponía la nueva escalinata de bajada desde la carretera, en el extremo suroeste del espacio de la plaza, con una planta triangular delimitada por la fachada del pabellón del monasterio, el que sobresale respecto del claustro de las Nereidas, y la carretera de Sarria a Pedrafita del Cebreiro, por el lado opuesto. Desde esta nueva escalera se bajaba a un camino pavimentado con losas de granito rectangulares, que permitía una comunicación central, directa y segura con la escalinata de acceso al templo. Asimismo, se planteaba una escalera secundaria, de mucha menor dimensión que la anterior, en la esquina noroeste de la plaza.

Tanto la ampliación del tramo de carretera inmediato al templo, como la reforma de la plaza previamente descrita, fueron obras ejecutadas con anterioridad al acto de inauguración del monasterio reconstruido, el 14 septiembre de 1960, algo que se puede comprobar con la observación de las fotografías tomadas durante esa jornada. Sin embargo, durante los años posteriores, Juan Monleón planteó continuar los trabajos de adecuación de la plaza a través de la creación de dos nuevos caminos, uno que comunicara el ya construido con la portería del monasterio y otro que, partiendo de la escalerita noroeste, terminase en la entrada del templo. Estos dos nuevos caminos se proponía pavimentarlos de igual forma que el ya construido, es decir, con losas rectangulares de granito, sentadas sobre firme y unidas entre sí. Al mismo tiempo, Juan Monleón planteaba pavimentar el resto de la superficie de la plaza con losas irregulares de piedra de granito yuxtapuestas y dejando entre ellas cierta separación para reducir gastos y permitir que entre las piezas pudiese crecer alguna hierba.

Este último proyecto, dibujado en noviembre de $1964,{ }^{69}$ no se llegó a materializar en su totalidad. De él se tomó la idea de unir la escalerita noroeste con el acceso al templo y, desde ese punto, se prolongó hasta la entrada al monasterio, con un camino de tierra, sin pavimentar, similar al que se trazó entre la escalera de bajada a la plaza y la portería del monasterio. El resto de la superficie se mantuvo como área ajardinada. ${ }^{70}$

\section{La inauguración de un nuevo monasterio}

El 27 de enero de 1960, el periódico $A B C$ informaba, en su edición de la mañana, de la proximidad

${ }^{69}$ AMS, Proyecto de reconstrucción del monasterio tras el incendio de 1951, carpeta VII, plano VII-22 y "Memoria sobre la pavimentación de la Plaza de la Iglesia de San Julián en Samos".

70 Así permaneció la plaza hasta el año 2012, cuando los dos caminos de tierra existentes se pavimentaron con losas de granito, de forma similar al que comunicaba la escalera de bajada desde la carretera con el acceso a la escalinata del templo. 
del término de las obras de reconstrucción del monasterio de Samos y de su probable reapertura durante el verano siguiente. ${ }^{71}$ Pocos meses después, la fecha del acto de inauguración de la recién reconstruida abadía se fijaba para la primera quincena de septiembre, tal y como anunciaba $L a$ Vanguardia Española de 26 de julio de 1960. ${ }^{72}$

A partir de ese momento se sucedieron las noticias que trataban de dar a conocer los trabajos realizados en la casa religiosa desde el trágico suceso de 1951. El 20 de agosto de 1960, Alejandro Armesto, en un reportaje especial del $A B C$, subrayaba que de la magnitud de la obra ejecutada daban una idea cabal las siguientes cifras: "...el monasterio tiene una superficie total de 10.180 metros cuadrados, de los cuales 2.560 están pavimentados en mármol, 2.300 con baldosa, 2.500 con madera y 1.850 con piedra. En los trabajos de reconstrucción se invirtieron unos 295.000 ladrillos, 1.800 toneladas de cemento y 210 de hierro. La cantería de granito utilizada, traída en su totalidad de otro pueblo de la provincia lucense, de Parga, representó 875 metros cúbicos y la madera para pisos, ventanas y puertas, éstas exclusivamente de castaño, 1.125 metros cúbicos. Se cubrieron de cristales 885 metros cuadrados y las pinturas de paredes y techos representan una superficie de cerca de 45.000 metros cuadrados. Fueron empleados 12.000 metros de tubo 'bergman' para la instalación eléctrica y los cables de conducción del fluido rebasan los 32.000 metros". 73

Sin embargo, aunque los trabajos ya realizados eran numerosos, la prensa de la época recordaba que todavía faltaba mucho por hacer. Señalaba Francisco Rivera en un artículo publicado en 1960 que "Ahora es necesario atender a su instalación $y$, a tal fin, la Orden Benedictina, deseosa de hacer a cualquier español partícipe de su gozo y su alegría por esta reconstrucción, le brinda la oportunidad de adoptar la celda de un monje, la sala capitular, la biblioteca u otra dependencia monacal y, en agradecimiento, un monje orará diariamente por el donante, por su familia (...) El patrocinio de estas instalaciones se hará a base de las siguientes cantidades: Doscientas pesetas para el pupitre de un alumno; 600 para la mesa de un profesor; 500 para un banco de la iglesia; 2.600 para una mesa de lectura de la biblioteca; 10.000 para cada vidriera de la iglesia y sacristía; 6.000 para una celda de un monje; 50.000 para la sala capitular; 25.000 para el oratorio; 100.000 para la biblioteca; 40.000 para el salón de estudios; 30.000 para un aula pedagógica. El Monasterio admite también libros, objetos de altavoces para la iglesia, refectorio, aulas, sillerías, etc" ${ }^{74}$

De los trabajos de reconstrucción realizados todas las publicaciones de la época coincidían en recalcar el respeto por lo tradicional y la búsqueda, al mismo tiempo, de funcionalidad y modernidad. El monasterio mantenía la esencia del destruido por el incendio, gracias a la conservación íntegra de la estructura pétrea original; recuperaba el aspecto y carácter del edificio original y empleaba los recursos de la técnica moderna, de forma consecuente con las directrices internacionales de actuación en el campo de la restauración, vigentes en aquella época.

La inauguración del monasterio reconstruido tuvo lugar el 14 de septiembre de 1960, con la presencia del Jefe del Estado y las principales autoridades nacionales y regionales, del gobierno y de la Iglesia. ${ }^{75}$ Ese mismo día se había programado el acto de apertura del I Curso de Sociología y Economía Rural que tuvo lugar en la sala capitular del monasterio, que comenzó con una intervención del abad de Samos, dirigida al Jefe del Estado, de la que, a continuación, reproducimos un fragmento, por considerarlo significativo para comprender las intenciones y carácter de los trabajos efectuados: "Hemos dicho reconstruido, y no restaurado, porque entendemos que restaurar significa levantar o rehacer lo caído devolviéndolo a su primitivo estado y condición, mientras que reconstruir equivale a volver a construir sobre las antiguas trazas, pero tomando de ellas lo mejor, lo genuino, aquello que es digno y merece ser conservado y perpetuado tomándolo como base y cimiento, al propio tiempo que se corrigen y enmiendan las deficiencias, los defectos, los anacronismos de tiempos pasados, situándolos en los momentos actuales, resolviendo sus problemas y

\footnotetext{
71 "Veintiún millones de pesetas...", 1960, p. 47.

72 "El monasterio de Samos prepara...", 1960, p. 4.

73 ARMESTO, Alejandro, 1960, p. 52.

74 RIVERA MANSO, Francisco, 1960.

75 Sobre el acto de inauguración del monasterio de Samos tras su reconstrucción, ARIAS CUENLLAS, Maximino, 1992, p. 494; PORTILLA COSTA, Pedro de la, 2003, pp. 55-56; GARRIDO MORENO, Antonio, 2008, p. 187; "La gloriosa abadía...", 1960, p. 5; GOZALO, Miguel Ángel, 1960, pp. 1, 5; "Franco inauguró...". El Ideal Gallego, 1960, pp. 1, 3-4.
} 
dificultades con acertada adaptación, sin exotismos ni plagios serviles, a las modalidades y exigencias nacidas de los progresos de la técnica y de la evolución de la Humanidad". ${ }^{76}$

Con la reapertura del monasterio se ponía fin a nueve años de intenso trabajo y se recuperaba la vida conventual propia del periodo anterior al siniestro, aunque con una comunidad mermada en su número de miembros. A través de una inscripción grabada en una placa ubicada en la escalera neogótica del claustro de la Nereidas se inmortalizaba el recuerdo del incendio y de las obras de restauración realizadas hasta 1960 .

\section{Conclusiones}

Se ha intentado en este artículo descubrir y dar a conocer, por una parte, la multitud de trabajos de restauración que fueron llevados a cabo en los dos claustros del monasterio de Samos para hacer posible la continuación de una vida en comunidad, tras el parón que supuso el incendio de 1951 $y$, por otra parte, hemos tratado de hacer visibles los numerosos cambios que todos esos trabajos causaron en la fábrica monacal existente antes del referido fatídico suceso. Quizás, fueron estos trabajos de reconstrucción los que, dentro del siglo $X X$, más modificaron la imagen tradicional del monasterio $y$, sin duda, también son los que mayor incidencia tienen en la apariencia actual con la que se muestra este monumento. El estudio detallado de las pérdidas, de los proyectos planteados para cada espacio y de los resultados de las obras realmente realizadas, permite conocer con claridad cuál fue el verdadero papel de Juan Monleón Sapiña en la definición de la nueva arquitectura a partir de la existente, saber qué partes de lo antiguo se mantienen y cuáles fueron completamente transformadas, así como entender el porqué de las decisiones tomadas en cuanto a los criterios de actuación. Factores todos estos que, en definitiva, son imprescindibles para leer correctamente la arquitectura actual de un conjunto con una larga trayectoria histórica.

\section{Bibliografía}

ARIAS CUENLLAS, Maximino. Historia del monasterio de San Julián de Samos. Samos: Monasterio de Samos /Diputación Provincial de Lugo, 1992.

ARMESTO, Alejandro. "Del fuego surge un nuevo Samos. El famoso monasterio benedictino, completamente restaurado, se inaugura próximamente". $A B C$,
20 de agosto de 1960, p. 52. En: <http://hemeroteca. abc.es/> (Fecha de consulta: 16-2-2009).

Carta de Atenas, 1931. En: http://ipce.mcu.es/conserva cion/intervencion.html (Fecha de consulta: 31-102013).

CASTRO FERNÁNDEZ, Belén. Francisco Pons-Sorolla y Arnau, arquitecto-restaurador: sus intervenciones en Galicia (1945-1985). [CD-ROM]. Santiago de Compostela: Servizo de Publicacións e Intercambio Científico da USC, 2007, pp. 529-535.

DURÁN, Miguel. La Real Abadía de San Julián de Samos: estudio histórico-arqueológico. Madrid, 1947.

"El monasterio de Samos prepara con grandes fiestas su reapertura". La Vanguardia Española, 26 de julio de 1960, p. 4. En: <http://www.lavanguardia.es/hemero teca/> (Fecha de consulta: 5-2-2010).

"Franco inauguró ayer el reconstruido Monasterio de Samos". El Ideal Gallego, 15 de septiembre de 1960, pp. 1, 3-4.

GARRIDO MORENO, Antonio. "Juan Monleón Sapiña. Proyectos y reformas en el monasterio de Samos (1951-1976)". En: FOLGAR DE LA CALLE, M. ${ }^{\text {a }}$ del Carmen y GOY DIZ, Ana E. (dirs.). San Xulián de Samos: Historia e arte nun mosteiro. Opus Monasticorum III. Santiago de Compostela: Xunta de Galicia, 2008, pp. 181-191.

GOZALO, Miguel Ángel. "Samos, otra vez en pie, a los nueve años del incendio que lo destruyó". El Ideal Gallego, 14 de septiembre de 1960, pp. 1, 5.

"In memoriam: Don Miguel Durán Salgado". Boletín de la Real Academia Gallega, 1946-1950, 289-293, pp. 185-187. En: <http://academia.gal/publicacions> (Fecha de consulta: 14-6-2016).

"La gloriosa abadía benedictina de Samos resurge nuevamente de las ruinas". La Vanguardia Española, 15 de septiembre de 1960, p. 5. En: <http://www.lavan guardia.es/hemeroteca/> (Fecha de consulta: 5-22010).

"La reconstrucción del monasterio de Samos. Tres millones y medio de pesetas se han invertido hasta ahora en las obras". La Vanguardia Española, 25 de septiembre de 1954, p. 1. En: <http://www.lavanguar dia.es/hemerotecal> (Fecha de consulta: 5-2-2010).

LÓPEZ OTERO, Modesto. "Don Miguel Durán Salgado". Revista Nacional de Arquitectura, 1950, 103, p. 327.

LÓPEZ SALAS, Estefanía. "Las causas y las consecuencias del incendio de 1951 en el monasterio de San Julián de Samos. Nuevos datos para su estudio". Cuadernos de Estudios Gallegos, 2016, 63, 129, pp. 417-447.

PORTILLA COSTA, Pedro de la. Monasterio de San Julián de Samos. Historia de dos restauraciones (1880 y 1951). A Coruña: Fundación Caixa Galicia, 2003.

RIVERA MANSO, Francisco. "El monasterio de Samos, reconstruido". Vida Gallega, 1960, 64. Sin paginar.

SEGOVIA MARTíN, José Carlos. Indicios y aportaciones del futurismo en la arquitectura española. Tesis doctoral. Escuela Técnica Superior de Arquitectura de Madrid, 2001.

"Veintiún millones de pesetas se han invertido hasta ahora en la reconstrucción del monasterio de Samos". $A B C, 27$ de enero de 1960, p. 47. En: $<$ http://hemeroteca.abc.es/> (Fecha de consulta: 16-22009).

76 "Franco inauguró...", 1960, p. 3. Reproducida por GARRIDO MORENO, Antonio, 2008, p. 187. 